\title{
How Domestic Violence Influences Academic Achievements of Students
}

\author{
Mrs. Bhawna Sharma ${ }^{1}$, Dr. Manisha Basal ${ }^{2 *}$, Dr. Rashmi Gupta ${ }^{3}$
}

\section{ABSTRACT}

A key goal of education is to ensure that every student has a chance to excel, both in school and in life. School performance in high school level depends on a student's mental and physical abilities which are influenced by other factors also. Studies carried out in a wide variety of countries demonstrate that the Domestic violence influences to a great extent the educational achievements as well as co-curricular achievements of the students. The data used for the analysis is gathered from the students of $9^{\text {th }}$ and $10^{\text {th }}$ graders. The home has a great influence on the child's psychological, emotional, social and economic state. The present study will also enable to improve students' performance and reactions to the life situations and necessary psychological support can be provided from time to time. The study also reveals that the students whose parents have better jobs and higher levels of income have high academic achievements as compared to the students whose parents have lower level job \& and lower levels of income.

Keywords: Domestic Violence, Academic Achievements, Health, Socio-Emotional

Academic Achievement is an important parameter in measuring success in students. The domestic violence is such a factor which is the foundation for children's development, as such in terms of family problems, family's socio-economic status and plays a vital role in educational achievements of the students. The home has a great influence on the child's psychological, emotional, social and economic state. This is because the domestic violence in context to the child's performance affects his reaction to life situations and his level of performance. The success at school is associated with domestic violence factors, as these factors can greatly affect young children's cognitive skills. Disadvantaged children (Children with poor social background and facing more number of domestic violence factors) start schooling with significantly lower cognitive skills than their more advantaged peers.

\footnotetext{
${ }^{1}$ Asstt. Professor, Department of Education, Hawabagh Women’s College, Jabalpur (M.P.)

${ }^{2}$ Asstt. Professor, Head, Department of Psychology, Hawabagh Women’s College, Jabalpur (M.P.)

${ }^{3}$ Asstt. Professor, Department of Education, Hawabagh Women’s College, Jabalpur (M.P.)

*Corresponding Author

(C) 2015 I B Sharma, M Bansal, R Gupta; licensee IJIP. This is an Open Access Research distributed under the terms of the Creative Commons Attribution License (http://creativecommons.org/licenses/by/2.0), which permits unrestricted use, distribution, and reproduction in any Medium, provided the original work is properly cited.
} 


\section{METHOD}

Data from $9^{\text {th }}$ graders and $10^{\text {th }}$ graders was collected to measure and compare the domestic violence and its influence on the students academic achievements. The sample size was one thousand. The data analyzed was derived from students by means of Domestic violence questionnaire where the students were asked about family and social background. The study made use of survey design where stratified and simple random sampling techniques. A selection of five hundred female students and five hundred male students were taken for the study. The study made use of both primary and secondary data. The primary data included data on domestic violence and parental socio economic status, whereas secondary data included data on the academic achievements of the students Data on Domestic violence and parental socio economic status were obtained through he administration of copies of structured questionnaire to the students.

\section{Pattern of Students Academic Achievement;}

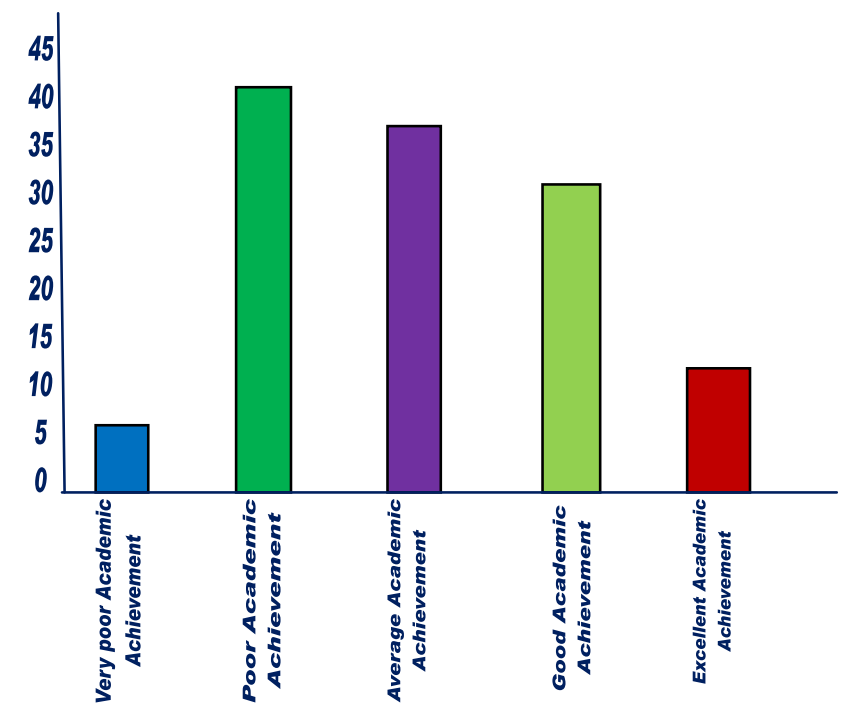

Effect of Domestic Violence on the group of Populations;

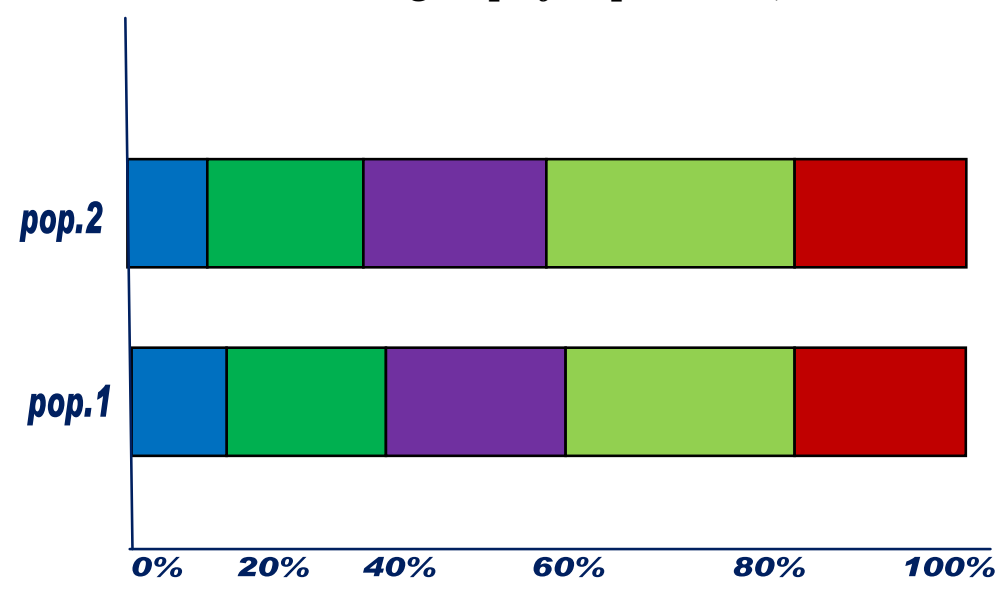


How Domestic Violence Influences Academic Achievements of Students

\section{Not successful \\ Less successful \\ Successful}

Average

Very Successful

\section{RESULT AND DISCUSSION}

Information on the sex, religion, ages, family type and family structure of respondents shows that 992 respondents have been able to answer the questionnaire. Here we find that in the $9^{\text {th }}$ graders and $10^{\text {th }}$ graders there is high correlation between the parents education \& domestic violence. The lesser the education of the parents the more is the level of domestic violence and vice versa.

\section{CONCLUSION}

As pointed out in the beginning of this article, it is the intension of the researcher to find out the relationship between Domestic violence and Academic the result of this study indicates that Domestic Violence does determine student's academic performance. This is because family background, students whose parents have better jobs and higher levels of educational attainment and who are exposed to more educational and cultural resources at home tend to have higher levels of literacy performance. In order to improve students' academic achievements add reactions to life situations irrespective of their domestic violence, parents are encouraged to have family size they can adequately cater for to the maximum.

\section{REFERENCES}

Eweniji, G.D. (2005) The Impact of Family Structure on University Student's Academic Performance. Olabisi Onabamijo University, Ago-Iwoye. Online.

OECD/UNESCO - UIS (2003) Family Background and Literacy Performance. http://www.oecd.orgdataoecd/43/9/33690591.pdf.

Osunloye, A. (2008) Family Background and Student Academic Performance. http://socyberty.Com/education/family-background-and-student-academicperformance.

Performance of Nigerian University Students. Stad Home Comm Sci, 2(2): 121-124.

Uwaifo, V.O. (2008) The Effects of Family Structure and Parenthood on the Academic 